\title{
12. Regulating international educational internships: Opportunities and challenges
}

\section{Joanna Howe}

\subsection{INTRODUCTION}

At the boundary between education and employment, there is a 'pragmatic ambiguity' that inheres in educational internships. ${ }^{1}$ An internship (commonly referred to as a 'traineeship' in Europe) is 'typically used to cover a wide range of schemes that seek to provide skills, knowledge and experience in a workplace'. ${ }^{2}$ The broad, varying and fluid nature of schemes that may be categorized as internships creates both opportunities and challenges. These arise from the mixed purposes of an educational internship and the multi-faceted identities of those involved. On the one hand, there is a context of employment, or at the very least the potential for employment or the appearance of employment, between an employer and a worker and the context for their interaction is the workplace. On the other hand, the nature and arguably primary purpose of an internship is educational, with the worker as a student. Other parties are also involved, including education institutions, academics and third parties who facilitate internships. In some cases the relevant work is carried out for the educational institution itself, so that the institution wears two hats: employer and educator. Thus, educational internships, although presenting many opportunities for those involved, are incredibly complex to regulate. ${ }^{3}$ This complexity is heightened considerably when the educational internship is overseas.

1 Maria Laura Toraldo, Mark Smith and Gazi Islam, 'Navigating Pragmatic Ambiguity: Career Identity in an Emerging Work Category' (31st EGOS Colloquium, Athens, Greece, July 2015).

2 Andrew Stewart, Rosemary Owens, Anne Hewitt and Irene Nikoloudakis, 'The Regulation of Internships: A Comparative Study’ (2018) ILO Employment Policy Department Working Paper No 240, xi.

See eg Niall O'Higgins (ed), Rising to the Youth Employment Challenge: New Evidence on Key Policy Issues (International Labour Office 2017); Stewart and others (n 2). 
A corollary of globalization - a term that defies precise definition ${ }^{4}$ - international educational internships are an emerging work and education category that responds to the internationalization of education and the global movement of workers. Facilitated by computer and technological developments and the associated information and communications revolutions, globalization has gained momentum by the progressive opening up of national economies (especially through trade liberalization), the ease with which corporations have adapted to a new world without borders, the increased international flows of capital and the consequent growth of international business. ${ }^{5}$ Universities, charged with educating and equipping the workers of the future, are now under increasing pressure to be globally focused and offer international experiences and opportunities to their students.

This chapter examines 'international educational internships', which refers to internships that are undertaken for the purpose of study at a particular institution but in a different country to that in which the institution is located. This is distinct to situations where a student goes abroad to study and does an internship while in the host country for their studies. The latter situation refers to what is typically understood as 'international students'. Here I focus on local students who travel abroad for an internship as part of their degree, or international students who travel to an overseas country other than that in which their studies are being undertaken. Although the discussion in this chapter of the complexity and challenges in regulating international educational internships is relevant for any country that seeks to regulate these arrangements, whether as the destination country or the country in which the relevant institution is based, I specifically draw upon an Australian empirical study on the regulation of work experience in 16 universities. This chapter uses this study to consider the emerging regulatory landscape and the regulatory opportunities and challenges created by international educational internships. It commences with a discussion of how this particular category of work and employment has arisen, and how it might be conceptualized. This is followed by a presentation and discussion of the empirical study, in light of the regulatory implications

4 See Catherine Dauvergne, Making People Illegal: What Globalization Means for Migration and Law (Cambridge University Press 2008) 29: 'the term globalization has grown out of control. There is no longer much to be gained in pinning down a definition for this shape shifter. Rather, it makes sense to use it with full consciousness of the fluidity and its inevitable incorporation by reference of lawyers of meaning from the popular to the erudite.'

5 Joanna Howe and Rosemary Owens, 'Temporary Labour Migration in the Global Era: The Regulatory Challenges' in Joanna Howe and Rosemary Owens (eds), Temporary Labour Migration in the Global Era (Bloomsbury 2016). 
and risks of international educational internships and the extent to which these are currently understood and addressed.

\subsection{CONCEPTUALIZING INTERNATIONAL EDUCATIONAL INTERNSHIPS IN AUSTRALIA}

Work experience, in the form of internships, is increasingly regarded as an essential transitional form of learning designed to bridge academic education and the workplace. This emphasis on students' employability has arisen at the same time as the internationalization of education, with a new concern with giving students global education experiences through study abroad or exchange programmes. Combined, this has resulted in the rise of international educational internships. Although some studies have focused on whether international educational internships affect employers' recruitment decisions, ${ }^{6}$ how educational institutions prepare students for overseas work experience ${ }^{7}$ or the perspectives of students participating in international educational internship programmes, ${ }^{8}$ there has not been a focus on the regulatory architecture framing and supporting the experience of students as workers in a foreign labour market. This is surprising given the emergence of a strong scholarly interest in Australia on the experience of international students as workers in the Australian labour market and the consensus view that these students are typically vulnerable workers employed in industries with a norm of non-compliance. ${ }^{9}$ This attention to international students in remunerated work has also been accompanied by a scholarly focus on the experience of international students in unpaid work through unpaid trials, internships or other forms of work experience. ${ }^{10}$

6 Christof Van Mol, 'Do Employers Value International Study and Internships? A Comparative Analysis of 31 Countries' (2017) 78 Geoforum 52.

7 David Engstrom and Loring P Jones, 'A Broadened Horizon: The Value of International Social Work Internships' (2007) 26 Soc Work Educ 136.

8 Elizabeth Huettman Roberts, 'The Innocents Abroad: Do Students Face International Internships Unprepared?' (1998) 39 Cornell Hotel Restaur Adm Q 64.

$9 \quad$ See eg Alexander Reilly, Joanna Howe, Laurie Berg, Bassina Farbenblum and George Tan, International Students and the Fair Work Ombudsman (Fair Work Ombudsman 2017); Alexander Reilly, 'Protecting Vulnerable Migrant Workers: The Case of International Students' (2012) 25 Aust J Lab L 181; Iain Campbell, Martina Boese and Joo-Cheong Tham, 'Inhospitable Workplaces? International Students and Paid Work in Food Services' (2016) 51 Aust J Soc Iss 279; Joanna Howe, 'A Legally Constructed Underclass of Workers? The Deportability and Limited Work Rights of International Students in Australia and the United Kingdom' (2019) 48 ILJ 416.

10 See eg Joanna Howe, Andrew Stewart and Rosemary Owens, 'Temporary Migrant Labour and Unpaid Work' (2018) 40 Syd L Rev 183; Lisa Ruhanen, Richard Robinson and Noreen Breakey, 'A Foreign Assignment: Internships and International 
In contrast, there has not been a sustained focus on Australian local students travelling and working overseas as part of an international educational internship. Yet these students are likely to share many of the attributes that make international students vulnerable in the Australian workplace. Both groups typically involve young people with limited experiences of paid and unpaid work, with aspirations of securing a positive reference and vital skills and experience from an internship in order to further their future career. Many Australian students involved in an international educational internship will be in a non-English-speaking country where they will be speaking a language less familiar to them. Most will be in a country where they have not been before, and have limited networks and scant knowledge of that country's laws pertaining to employment, and where the culture and societal norms and expectations are vastly different. Each of these aspects has the potential to make students who undertake international educational internships vulnerable in the workplace. Thus, while international educational internships are being pursued as part of a global mobility education agenda, there is a need to better understand the way these work experiences are framed, marketed and supported by education providers, and the extent to which education providers are cognizant of some of the potential challenges which arise in this emerging form of work-integrated learning.

\subsection{THE APPLICATION OF LABOUR REGULATION TO CROSS-JURISDICTIONAL WORK BY EDUCATIONAL INTERNS}

An important aspect of the complexity of international educational internships is that the internship occurs in a different country to that in which the student's education is being undertaken. Different countries take radically different approaches to the regulation of work performed by educational interns. It is also not straightforward to determine which laws apply in the performance of cross-jurisdictional work. This section briefly introduces and explores these complexities.

There is no uniform approach internationally to whether educational internships are brought within the scope of labour regulation. ${ }^{11}$ Labour regulation is a broad term that encompasses a range of laws that affect the employment relationship. In some countries, for example, educational interns are covered

Students' (2013) 20 J Hosp Tourism Manage 1; Cate Gribble, Employment, Work Placements \& Work Integrated Learning of International Students in Australia (Research Digest 2, International Education Association of Australia 2014).

11 See generally, Stewart and others (n 2) ch 8. 
by the same health and safety laws that govern employees, and this is often so for equality or anti-discrimination laws. However, other forms of labour regulation concerning minimum wages, working hours and protection from unfair dismissal are much less likely to cover educational interns. For example, in Australia, when a student undertakes an internship as part of their studies, this is categorized as a 'vocational placement' and, as a consequence, the student is not entitled to minimum wages, leave entitlements or other employment-related benefits or protections. ${ }^{12}$ In some countries, notably Argentina, France and Romania, the exclusion of educational interns from the benefits of labour regulation is compensated for by the detailed regulation of the relationships between the intern, the institution at which they are studying and the host organization for the internship. ${ }^{13}$ The different arrangements by which educational interns are covered by labour regulation in various countries create immense complexities for students, host organizations and educational institutions in arranging and facilitating international educational internships.

A related challenge is that the law relating to cross-jurisdictional work is very complex. It can be hard to determine which law applies in situations where an employment relationship has a cross-jurisdictional dimension, for example, since the employer is from a different country to the employee, or in situations where an employee is working abroad. This complexity is exacerbated in relation to international educational internships because there is an overlay of ambiguities about the categorization of work experience and its regulation in labour law. Nonetheless, if work has a connection to more than one jurisdiction, the rules of private international law provide answers to disputes about jurisdiction and choice of law. ${ }^{14}$ It can generally be assumed that local labour laws will apply as a matter of public international law on the basis of their 'mandatory' status. However, this is not always so, for example, when there are specific carve outs in free trade agreements ${ }^{15}$ or in situations (as in Australia, mentioned previously) where a local law has a vocational placement exception. One way parties have resolved cross-jurisdictional

12 Fair Work Act 2009 (Cth) ss 13, 15, 30C, 30M.

13 Stewart and others (n 2) 51.

14 See generally, Reid Mortensen, Richard Garnett and Mary Keyes, Private International Law in Australia (3rd edn, LexisNexis Butterworths 2015) ch 4.

15 See eg Joo-Cheong Tham, 'Trade Agreements and Australian Labour Law: Implications of the Death of the Trans-Pacific Partnership Agreement' in John Howe, Anna Chapman and Ingrid Landau (eds), The Evolving Project of Labour Law: Foundations: Development and Future Research Directions (Federation Press 2017); Samuel Engblom, Nicola Kountouris and Åsa Odin Ekman, 'Temporary Labour Migration and the Trade in Services: European and Global Perspectives in an Age of Economic Integration' in Joanna Howe and Rosemary Owens (eds), Temporary Labour Migration in the Global Era (Bloomsbury 2016). 
complexities in employment contracts is to agree that a particular country's law is to be regarded as the 'proper law' governing the contract, ${ }^{16}$ and this is generally respected by the courts, except in situations where there may be a clear statutory presumption that the statute is to apply to work performed in a particular country. ${ }^{17}$ However, it is unlikely that these clauses are commonplace in placement contracts for students involved in international educational internships, as these types of internships are a new and developing phenomenon. Moreover, if there were a dispute about the obligations in a placement contract, it might be a matter for the proper law of the contract, which might be the local law, the law of the country where the institution is located or the law of a third country (for example, where a broker located elsewhere has drafted the contract).

\subsection{THE EMPIRICAL STUDY}

This chapter draws on data from a research project implementing a three-phase, mixed methodological approach to analyse the nature and extent of unpaid work experience in the Australian university sector. The methodology for this study is discussed elsewhere in this collection. ${ }^{18}$ Here I confine my analysis to the findings from this project in relation to international educational internships.

\subsubsection{Defining International Educational Internships}

It was striking from the university case studies that international educational internships are not homogenous and can be structured and organized in different ways. First, the overseas internship could pertain to local students (that is, Australian residents or citizens) taking up overseas work experience. It could also encompass situations where international students in Australia either go back to their country of origin to do an internship or go to another overseas country for an internship as part of their studies. The process for arranging an educational internship is also potentially subject to a number of different variables. The arrangement could be organized by the university dealing directly with a host (for example, an overseas business, government entity or charity), the student acting alone and directly organizing the host, or through

\footnotetext{
16 Martin Davies, Andrew Bell and Paul Le Gay Brereton, Nygh's Conflict of Laws in Australia (9th edn, LexisNexis 2014) 441-56.

17 Andrew Stewart, Anthony Forsyth, Mark Irving, Richard Johnstone and Shae McCrystal, Creighton and Stewart's Labour Law (6th edn, Federation Press 2016) [6.23].

18 See Chapter 13 in this volume.
} 
a third party, such as a commercial broker who may be based in Australia, in the host country or in another country. Another possibility is situations where the internship is facilitated through a direct government arrangement between two countries (such as the New Colombo Plan) but involves universities and businesses. These different dimensions of how an international educational internship could be accessed and arranged were reflected in the interviews.

There was significant variation in how international educational internships were understood and discussed by the interviewees in our study. Some students organized their own international internship, while others applied for this opportunity through their university with an overseas employer who had an established arrangement with the university. Some universities offered study abroad experiences which included a practical component, whereas others arranged straight internships. One interviewee reported 'quite a lot of growth' and 'much stronger student interest' in international educational internships through greater variation in their structure, via short-term programmes, and mixed programmes with both a study and applied component.

The interviewees regarded international educational internships as important for improving students' employability in a global labour market. Many universities appeared to be developing pathways and opportunities for students to be involved in an international internship as part of their degree. A number of the universities involved in the study had established new positions for high-level university administrators such as 'Pro-Vice Chancellor for Community and Global Engagement' and new central divisions such as 'Global' or 'Global Mobility'.

In some instances, overseas educational internships were paid, although it was more common for interviewees to refer to international educational internships as unpaid. A number of interviewees suggested that overseas educational internships had a humanitarian component (more so than domestic ones), with students working for charities and other non-government organizations to meet a specific social justice need overseas. In contrast, an academic reported that it was not uncommon for students to seek to rebadge overseas volunteer work as part of a course. She stated, 'they come to me and asks if that counts ... Sometimes it does, most of the time it doesn't because they're going to be in Africa to build an orphanage and that's not work experience in the way that's defined by the university'. In other instances reported by interviewees, an overseas experience was formally designated as an internship by the university but did not involve a genuine work experience. One interviewee stated:

We have placements where a small group of students has gone overseas and that's all been organized through the school and not us [centrally] ... from my understanding they call it an internship, but it's been more of an observation where they've gone as a group to visit certain universities and then a workplace. 


\subsubsection{Processes for Establishing and Managing International Educational Internships}

The interviewees identified that the lack of homogeneity in how international educational internships are sourced and managed makes it difficult for universities to develop a uniform and consistent approach. Across each of the university case studies this appeared to be an area that was in a state of flux, with very limited centralized processes for establishing and managing international educational internships. Nonetheless, it was an area that was being promoted in many universities as part of a strategy to promote work experience as well as global experiences for students. Some universities even had specific targets, such as a commitment to ensure a certain percentage of their cohort graduate with an international work experience.

There was a sense conveyed by some interviewees that this was a growth area that was not being adequately regulated at present. One interviewee said, 'Where the student has sourced an international placement that's hard, because not only do we not know the partner but they're not even using our law.' Another interviewee reported, 'Our students are everywhere overseas, it's just frightening', alluding to the myriad administrative challenges in organizing and overseeing international educational internships. A number of interviewees suggested that their university had not yet adequately developed processes for sourcing and managing international educational internships. In the absence of adequate structures within the university at the central level, some academics voiced concerns such as: 'We're still in a state of flux' and 'There isn't a lot of direction from the top'. Some academics attempted to manage this challenge by developing their own partnerships with overseas host employers.

In another interview, a university administrator voiced her perception that the strong institutional understanding of the legal requirements around internships in Australian workplaces was not matched by an understanding of employment law requirements in overseas workplaces. She observed: 'Probably the greyest area for me are the international-based internships or placements that, you know, that we've got students in a foreign country and there's, things that can go wrong and I'm not sure we have that really worked out as well as we could do.'

Across all the institutions we examined, there appeared to be some understanding of the importance of safety, although this was largely interpreted as being about the physical safety of a student travelling to a particular country rather than occupational health and safety issues in a foreign workplace. As one interviewee stated, 'There's a great deal of emphasis and support on keeping students safe in travelling, but that's not necessarily associated with work.' A number of institutions appeared to have reasonably developed processes around managing safety, including preventing students from doing internships 
in countries perceived as high risk. For example: 'So if we're approached by an organization from the Congo for example, I would automatically say "no" because we're not going to put our students at such a high risk.' Another interviewee stated, 'We had a student the other day that wanted to go to North Korea and someone in the school signed off on it ... so we interceded on that occasion.' A number of universities had protocols in place which involved risk management plans for any overseas placements or exchange, provision for international emergency student air services and a free 24-hour telephone hotline which students could call in emergencies. Typically, universities contracted with third parties to provide overseas support services such as these to their students. One university referred to a mobile tracking service that it used to identify the locations of its students when overseas. Across the universities there seemed to be a strong desire to manage personal safety risks arising from overseas educational internships. One interviewee stated, 'So you try to think of every possibility, every possible risk that can take place and how you can remedy that risk before anything happens. You can't cover all possible scenarios but at least you can minimize them. And so we sort of have action plans in case anything happens.'

\subsubsection{University Protocols for Selecting Host Organizations for Overseas Internships}

Some, though not all, universities did site visits for international educational internships, which on a few occasions appeared to take into account workplace issues and not just general safety concerns. However, most of the time it appeared from the interviews that site visits were extremely rare owing to the immense resources required to undertake site visits for internships in another country. However, site visits themselves can be of varying use as their effectiveness in identifying health and safety risks requires the person doing the visit to assess and understand safety systems in the workplace and to ensure that there are robust and established protocols around managing safety. At some universities, there appeared to be a level of assessment at the central level of whether an overseas internship opportunity should be pursued. In contrast, other universities had more devolved structures, relying on individual disciplines and academics to manage risks arising from international educational internships. For example, one interviewee observed that it is now common at their institution for an academic to travel with students undertaking work experience and to meet with an overseas host and assess their workplace prior to the placement. 


\subsubsection{Preparing Students Prior to an Overseas Internship}

A number of universities conducted pre-departure briefings for students, although again these appeared to focus on safety protocols and, in some cases, advice and training around cultural norms in their destination country, rather than on workplace laws, rights and occupational health and safety. As one interviewee stated, 'We don't actually deal with workplace harassment and health and safety and all that sort of thing explicitly. What we do is ... before they go overseas, part of the preparation involves a cultural orientation.' It appears that these pre-departure briefings and training tended to be organized centrally by the university, although some individual academics we interviewed took additional steps to ensure the well-being and safety of students while overseas. For example, one academic we interviewed reported:

One of the things about work-integrated learning being much more integrated across the university is finally there's some systems. So we now get them to register online through Global Mobility. Through that they do all sorts of crazy training stuff which I don't think are that good. And then they get given a phone number and so if they need to be air-vacced out or whatever else they can just call that number. But that's not the kind of emergency my students really feel. So I have a closed Facebook page so if they have an issue they can just tag me day or night. I also give my students in this class, everybody has my mobile phone number.

Although the genuine concern of this academic for her students was apparent in her additional efforts to support them while overseas, it is unlikely that individualized responses such as these to student vulnerability in overseas workplaces will be of substantial use. It may even be misleading because it provides a false sense that there is a system of safety for managing dangers and risks, when in reality no individual academic can offer 24-hour monitoring or emergency support from afar without broader institutional support and processes.

\subsubsection{The Use of Third Parties to Facilitate and Manage Overseas Internships}

A common feature across all the universities, with one notable exception, was the use of brokering firms to source and manage international educational internships. The absence of regulation of third-party internship providers and migration agents involved in cross-border mobility creates risk for universities 
as there are no regulatory barriers to entry or external standards which universities can rely upon when selecting which brokers to work with. ${ }^{19}$

Interviewees suggested that third-party brokers were essential to developing connections with overseas businesses and organizations to arrange placements. As one interviewee stated: 'There are these hesitations to using external providers ... but yet this is the only way we can get students to do overseas internship placements because no-one [within the university] has the contacts and the time to be able to do this across the world.' Most interviewees referred to robust processes for selecting brokering firms to manage the risks arising from contracting with a third party to place students overseas. As one interviewee stated: 'So internationally we work with a small number of third-party providers. There's extensive due diligence that goes into vetting those third-party providers in terms of their credentials.' It was common for universities to abdicate all responsibility for sourcing and managing overseas internships to a third party. For example, one interviewee stated:

We've got about three or four of these companies. They're not really brokers, they're partners, and so when we send kids over to do work, they're not looked after by anybody from us. We've got four or five partners that I can think of and so they become responsible for the student over there. They are the company in charge of the student while they are away. So we have kids going to India, Indonesia, China, Vietnam, and then of course the other ones which are Singapore and Cupertino.

Another interviewee referred to a situation where a student had made a complaint of sexual harassment during an internship experience in China. The student contacted the broker who had organized the internship on behalf of the university and was removed from the workplace and placed at an alternative workplace in China. According to the interviewee, 'I only heard about it the sexual harassment] after the student's return when we had a debrief but ... it

19 Paula McDonald, 'Open Market Internships: What Do Intermediaries Offer?' (2020) 33 J Educ \& Work 33. See also an investigation for the Sun Herald which uncovered exploitation of occupational trainees employed as 'interns' by a luxury hotel chain in regional New South Wales. The trainees paid $\$ 6500$ for the internship opportunity, a 52-week training contract, provided by a third party, Australian Internships: Anna Patty, "Australia's International Reputation "At Risk" Over Treatment of Visa Workers' Sydney Morning Herald (Sydney, 28 July 2019), https://www.smh.com .au/business/workplace/australia-s-international-reputation-at-risk-over-treatment-of -visa-workers-20190715-p527a5.html, accessed 30 March 2021; Anna Patty, 'Hotels Clawing Back Wages from Workers: Exclusive' Sun Herald (Sydney, 7 July 2019); Anna Patty, 'Staff at Luxury Hotel Group Threatened after Speaking Out about Exploitation' Sydney Morning Herald (Sydney, 9 July 2019), https://www.smh.com .au/business/workplace/staff-at-luxury-hotel-group-threatened-after-speaking-out -about-exploitation-20190708-p5258b.html, accessed 30 March 2021. 
was dealt with very quickly, within 24 hours actually'. However, it was unclear from the interview whether this incident led to a systemic outcome as the interviewee was unaware whether other students from the university were still sent by the broker to the workplace where an allegation of sexual harassment had been made.

Not all universities used brokers to both source and manage overseas internships. One university referred to using a 'company on the ground that actually finds the placements, but then we take responsibility'. This interviewee stated that this demarcation between the broker's role in sourcing placements and the university's role in vetting and managing them was instituted because they were 'very conscious of the risks'. The interviewee stated that the university had often rejected placements proposed by the broker on the basis that the university could not get enough information about the nature of the internship and could thus not guarantee its quality to its students.

Nonetheless, to avoid altogether the risks associated with third parties, one institution had a policy of organizing all overseas placements in-house rather than through a third-party broker. A representative from this university stated that they did not partner with any internship providers because of a feeling of 'nervousness around them because we sometimes worry about their intentions, as opposed to sort of the income generation [from arranging internships] rather than the quality of the experience'.

\subsubsection{Awareness of Migration Laws and Regulations by Universities}

A final issue that arose in the interviews pertaining to overseas educational internships was the migration arrangements used to facilitate students' travel and work overseas. There appeared to be a high level of confusion and/or a lack of general awareness of the types of visas that students used while on overseas educational internships. It did not appear that universities had systems in place to assist students in identifying and applying for visas. There was a general belief that students relied on tourist visas to travel overseas and work as interns, as these were easy to arrange, although some interviewees acknowledged an awareness that tourist visas generally do not permit visa holders to work in a foreign country. As one interviewee stated:

Normally you [students] get a tourist visa, just because if you're going to get a work visa or a business visa, it's a lot more complex, they ask you so many other questions and the process is just much longer and it's more expensive. So if you just get a tourist visa that covers you for a period of time, no questions asked, and you can do whatever you need to do and get out. 
In most of the universities we studied there was a poor understanding of the migration rules for internship agreements or, in some instances, a willingness to rely on a more easily accessible visa despite concern that it may be inappropriate for the type of travel involved. For students travelling overseas for an internship, holding an incorrect visa that does not permit a right to work during the visa holder's stay may prevent them undertaking the internship. For example, in 2015 a group of university students who had their internships arranged through a broker were unable to complete their internship in Singapore after it became clear that the broker had not arranged for the students to have a valid work visa. ${ }^{20}$

\subsection{CONCLUSION}

Our findings demonstrate that, despite the increased interest and growth in international educational internships, there is a high degree of uncertainty within universities about how to manage them. Although there is increasing scholarly attention on whether interns are 'employees' and thus fall under the scope of national labour laws, the focus of the universities in which we conducted interviews tended to be on international educational internships as learning experiences, in some instances involving volunteering or charity work, or a fusion of study abroad and work experience. It was extremely uncommon in the interviews for participants to refer to international educational internships as a form of employment. This perhaps contributed to interviewees not demonstrating cognizance that there are complex cross-jurisdictional issues in determining which labour laws apply to students undertaking overseas internships. Although some universities offered pre-departure training, this typically never focused on employment-related matters, and was more about cultural awareness training and safety protocols. Very few universities appeared to conduct on-site or even online audits and inspections of the overseas workplaces which were being used by their students as part of an international educational internship. When these site visits did occur, it was unclear how robust they were in identifying safety and other workplace risks to students. Each of these aspects suggests that most Australian universities do not seem to have adequate regulatory and oversight processes in place, although there is a clear drive among universities to promote growth in international educational internships. The presence of third parties, and in particular brokers,

20 Josie Taylor, 'Absolute Internship: Claims Students Left without Visas in Singapore Spark National Review' ABC News (Sydney, 12 March 2015), https://www .abc.net.au/news/2015-02-19/concerns-about-paid-overseas-internships-spark-national -review/6148634, accessed 30 March 2021. 
with a vested interest in promoting international educational internships also poses risks for universities and students. These risks include sending students to overseas workplaces that have not been subject to proper vetting processes, or outsourcing visa arrangements and safety management protocols to a broker who may not have adequate procedures in place. This appears to be a growing sector, as one interviewee stated: 'We get approached almost every day by brokers offering internships overseas.'

Perhaps as a result of the framing of international educational internships as international experience rather than work experience, most of the universities did not focus on managing risks arising from the workplace but appeared to concentrate their efforts on managing travel risks. Most universities focused more on developing travel guidelines, protocols and information for students going overseas and the few interview participants who mentioned the different labour laws in overseas countries acknowledged their lack of awareness of these laws or whether they applied to interns. Although students' physical safety overseas was the main aspect safeguarded by universities' central administration, a number of individual academics we interviewed referred to steps they took to verify and assess internship opportunities in other countries and to assist and support students undertaking international educational internships. Some of the strategies that academics referred to were to rely on personal contacts and networks to establish international internship opportunities, to provide their personal mobile numbers to students going overseas and to meet with students individually to discuss the internship. The resource-intensive and personal nature of these support efforts by individual academics may be difficult to replicate at a centralized university level, which is perhaps another reason why support services for students in overseas workplaces have tended to focus on the more generic issues of physical safety and cultural awareness training.

The research also identified a striking lack of awareness and engagement by universities with migration regulations permitting overseas travel. Interview participants did not demonstrate awareness of the types of visas being used by their students to conduct international internships and the few participants who did identify this suggested that their students were using tourist visas to undertake overseas internships. Tourist visas typically do not permit the visa holder to work, although there is often ambiguity as to whether this includes a prohibition against unpaid work. This poses risks for students when working in an internship abroad; if they are found to be on the incorrect visa, it could amount to a breach of that country's migration laws and regulations, and lead to visa cancellation and deportation. This poses reputational and other risks for universities who are keen to facilitate and promote growth in international educational internships. 
Thus, this exploratory chapter has pointed to the existence of a range of regulatory issues that pertain to international educational internships. Although universities appear to be increasingly promoting these opportunities to students, this appears to be taking place without the development of policies and procedures for arranging and managing these internships. There appears to be a consistent lack of understanding by Australian universities of the implications of labour law and migration law when internships are organized abroad. There also appears to be inadequate preparation for students undertaking international educational internships and measures to assess safety and other workplace risks and dangers, and processes for responding when undesirable situations arise. 